\title{
MSU MEDICAL COLLEGES BLENDED LEARNING FOR FIRST YEAR SCIENCE COURSES: UNITING PEDAGOGY TO MAXIMIZE EXPERIENCE AND REAL WORLD LIMITATIONS
}

\author{
Kathryn Lovell, Ph.D. \\ Director of Academic Computing \& Professor \\ College of Human Medicine \\ Michigan State University
}

Karen Vignare, Ed.S.

Director, MSUglobal

Michigan State University

\begin{abstract}
At Michigan State University the two medical schools, College of Human Medicine (CHM; M.D. degree) and College of Osteopathic Medicine (COM; D.O. degree), have offered the same science courses to first year students for many years. Science departments report to both colleges, and the same faculty can effectively teach the content required in the first year of medical school. The faculty have created online resources to maximize student choice and learning approaches. For example, classroom lectures (audio and screen video) are recorded; online homework may contribute to the course grade; virtual microscope software and material for histology laboratory is available online in addition to computer-based laboratory sessions with instructors present; and many practice exams are available online. MSU is expanding to three new campuses during the 2008-2010 period. CHM will open a sister campus in Grand Rapids, while COM will open two branch campuses in southeast Michigan.
\end{abstract}

The goal is to make the learning experiences equivalent for all students at all campuses. Faculty, staff and administrators have met on a regular basis to discuss working toward a NSF CyberInfrastructure model where all basic science learning experiences (with the exception of gross anatomy lab) are available online. These online resources will be coupled with face to face learning as well. Currently, efforts to make course materials available online in the most effective manner are underway. Discussion about how to provide online communication channels is also progressing. Numerous debates have occurred on how best to facilitate student learning in multiple locations using new technology tools, recognizing the goal for students is not only to pass medical board exams but also to acquire life-long learning skills in an ever changing medical and science environment. The authors will share not only processes used, but also perspectives on best approaches and strategies to determine what students find effective.

\section{KEYWORDS}

Medical Students, Blended Learning, Multiple Sites, Online learning, Cyberinfrastructure, Medical Education 


\section{INTRODUCTION}

\section{A. Overview and Expansion at Michigan State University Medical Schools}

At Michigan State University, the allopathic (College of Human Medicine; CHM; MD degree) and osteopathic (College of Osteopathic Medicine; COM; DO degree) medical schools teach the first year basic science courses jointly, with 356 students currently enrolled. The colleges are expanding in both number of students and number of locations, with goals to produce more primary care physicians that will practice in Michigan. CHM accepted 50 additional Year 1 students in fall 2007; those 50 will attend Year 2 classes at a new Grand Rapids campus in fall 2008. In fall 2010 there will be 100 students in East Lansing \& 100 students in Grand Rapids at sister campuses. Two years ago, COM increased from 125 to 200 Year 1 students, and will accept an additional 100 students and create two new campuses in southeast Michigan in fall 2009.

With the planned expansions, each Year 1 basic science course will be delivering content to 500 students at four sites. High resolution videoconferencing will be used to broadcast lectures to multiple locations. This paper describes a planning process for curricular delivery and design of online materials for blended learning in selected courses, as well as student input into the important features of online materials and communication.

The process was introduced as the Basic Science Distance Learning Initiative (BSDLI). Faculty met on a regular basis to discuss general principles of online learning, strategies for blended learning, and the potential implementation of curricular delivery based on the NSF CyberInfrastructure Model. Principles defined to guide consideration of learning options for multiple locations included the preservation and enhancement of:

course and and content quality

student learning options to accommodate lifestyles and learning styles

student learning efficiency and effectiveness

As part of the process, student surveys and focus groups were conducted to determine which approaches are important for students, and to assess effectiveness from the student point of view.

\section{B. Cyberinfrastructure Model}

The 'cyberinfrastructure' model is a term made popular by the National Science Foundation in 2007 [1]. The design of the cyberinfrastructure model is based on the need for super computing, instantaneous connectivity to all resources, and relationships among researchers, professors, observers and students. The MSU medical schools' expansion focused on using Internet connectivity to build more extensive relationships among the four campuses. This model moves education beyond the current old school classroom based approach. A ubiquitous learning environment is envisioned which connects classrooms, workplaces, home, laboratories, corporations, government offices and others to offer a new open learning environment. These new models for learning should allow for further collaboration, promote the ability to model and visualize complex concepts, assess learning gains differently, and allow students to personalize learning environments to meet their needs. MSU envisioned the best way to approach cyberinfrastructure was to phase it in using a blended learning solution.

The cyberinfrastructure model is based on relatively new work from neuroscience and cognitive science. According to Bransford, Brown and Cocking, students' needs vary and it is incumbent upon experts to 
build better learning systems [2].These systems need to be active and offer students different ways than multiple choice tests to interact with learning materials. The learning environments need to recognize the various stages of learning and the opportunities to learn from each other rather than reliance on text based materials. While the "How People Learn" research did not specify any specific type of learning, online asynchronous learning allows faculty to offer more pedagogical approaches and better connectivity to students.

\section{Blended Learning Solutions and Approaches}

The MSU medical school expansion stimulated discussion of increased integration of online learning and classroom approaches. While the classroom has been a successful model, there are many reasons, including pedagogical ones, for choosing to integrate online learning. At least one definition of blended learning discusses the opportunities and challenges of blended learning.

A "blended course" is the integration of online with face-to-face instruction in a planned, pedagogically valuable manner; and not just a combination (addition) of online with face-to-face but a trade-off (replacement) of face-to-face time with online activity (or vice versa) [3].

Since 1998, the University of Central Florida (UCF) has been using a similar definition for its blended learning courses termed mixed-mode courses [4]. The UCF data reveal that blended learning is effective and can lead to higher student success (grades) rates in specific academic disciplines. In addition faculty seem to be very satisfied with teaching either blended or online as long as they receive training and academic support [5]. Research by Garrison and Kanuka posited that blended learning is not only an acceptable methodology but a transformative one for higher education [6]. This view that online learning technology could transform learning was also suggested by Bransford et al in their book on "How People Learn" [2]. Hiltz and Turoff also strongly support the view that the introduction of asynchronous learning networks to campus courses will be viewed as a critical breakthrough in improving learning [7]. McCombs \& Vakili reached a similar conclusion because blended learning can lead to a more learnercentered education environment [8].

Online learning has been shown to be just as effective as classroom education and allows faculty an opportunity to rethink and redesign the course. When redesigning a course it is important to identify the distinct parts of the learning process: teaching, cognitive and social. Each of these parts and presences are critical to student success [9]. Using a "community of inquiry” model, teaching can spur the parts to collaborate and build, like the NSF CyberInfrastructure Model, a more dynamic learning environment.

The online learning environment provides students with structure when designed correctly. This environment affords students with clear instructions on what to learn and it requires them to participate fully in the learning process encouraging them to take more responsibility. The cognitive portion does remain similar to the classroom environment through testing and assessment. However, online methods can offer instructors the ability to track what students write or demonstrate online. In addition, the use of computer models or laboratory testing online offers not only a chance to assess students but a chance to offer students more practice, which is a critical part of long-term retention [11]. There are opportunities to problem solve through interactive cases studies or virtual patient simulations. 


\section{Blended and Online Learning in Medical Education}

The role of blended and online learning in medical education has been recently summarized [12, 13]. These articles described results supporting the concept that online learning is at least as effective as traditional instructor-led methods (e.g. lectures). Thus, in medical education, as other components of higher education, "traditional instructor-centered teaching is yielding to a learner-centered model that puts learners in control of their own learning." [12] An important element in development of interactive online resources for students is the creation of repositories or digital libraries to manage access to digital learning objects (e.g. images, diagrams, animations, interactive modules).

Implementation of asynchronous learning modules as part of blended learning strategies for science courses is very important, in part because of the large class size for many undergraduate and medical school science courses. A number of factors contribute to the large class size. Basic science faculty members' at large institutions are often under pressure to obtain grant funding and conduct research; this leaves less time for teaching assignments. In many cases, especially medical schools, there is a strong desire from students to have standardized instruction from the same individual for a given course, and from the best teaching faculty. The best way to accommodate these issues is often by having large classes with lectures and exams provided by a few experienced faculty members. In courses with laboratory sessions, smaller groups are scheduled, usually with graduate teaching assistants playing a key role in the individual instruction. Since the objectives and methods of the lab sessions are planned by faculty, the variation may not be a substantive issue and the availability of multiple teaching assistants can assist students with different types of questions and level of understanding. Often the application and problemsolving that may occur in a lab session is important to the understanding of complex concepts. Lab experiences are difficult to simulate online, both because of the "hands-on" experiences in many lab sessions and because of the application of knowledge required with more variation in learner styles and skills. Thus, both large class sizes and the complex nature of science content contribute to unique challenges for blended learning strategies

\section{METHODOLOGY}

\section{A. Process}

A coordinated effort began in spring 2007 with involvement of multiple campus units, including administrators in both medical schools, MSU Global, Virtual University Design and Technology, Blended Curricular Learning Resources (CHM), Health Information Technology-Educational Technology, MSU Libraries, and teaching faculty. Regular planning sessions were held (usually twice per month). Besides lecture delivery, strategies were discussed for development of interactive digital materials that can be shared. These would include multimedia objects for use without copyright fees (e.g. from Health Education Assets Library). Requirements for faculty support and features needed in a local searchable repository of re-usable learning objects were discussed.

\section{B. Student Survey}

To determine student preferences and perceptions, input was obtained from Year 1 students about the most effective use of online options. An online survey was sent to students at the beginning of the second year, asking for input related to the first year of medical school. Following compilation of results from the online survey, two focus group interviews were conducted. In each college, the Year 2 student curriculum liaison recruited other students. There were 6 students in the COM focus group and 8 students in the CHM focus group. Questions were posed to obtain more in-depth information about lecture interactivity and presentation options, communication methods, and approaches to online learning resources. From written notes and an audio tape, comments were grouped into topics. 


\section{RESULTS}

\section{A. Strategies for Improvements In Courses}

Development of online interactive modules has been planned and partially implemented for disciplines of biochemistry, physiology, histology, bacteriology, immunology, and neuroscience, with attention given to effective modalities for specific course objectives, focusing initially on difficult concepts. Faculty agreed it was important to make decisions on design and priorities according to pedagogical principles. (Some of the development described below was initiated prior to the Basic Science Distance Learning Initiative.)

\section{Biochemistry}

In the Biochemistry course, three lectures were replaced with online modules and a 2-hour interactive case conference using clickers was added. Faculty thought the new methodology achieved all goals, and replacement of additional lectures is planned.

\section{Cell Biology \& Physiology}

In the Cell Biology and Physiology course, which includes histology, introductory histology laboratory materials were provided, along with online exercises that contributed a very small amount to the student grade. These exercises had to be completed prior to the laboratory session so that students would be prepared to participate in the session. In addition, there were quizzes using clickers at the beginning of lab sessions, to ensure that each student completed the online exercises independently. Faculty thought lab sessions were more productive and efficient and students were better prepared.

\section{Neuroscience}

In the neuroscience course, there were pre-recorded lectures (using Camtasia Studio) for selected topics that replaced several lectures. Some class time was devoted to case presentations with live patients in the classroom to reinforce concepts in recorded lectures. Faculty thought content delivery was effective and cases were valuable. Students were enthusiastic about the patient case presentations.

\section{Microbiology and Immunology Course}

Virtual Interactive Bacteriology Laboratory (VIBL) modules were designed to simulate activities in two bacteriology laboratory sessions. The modules demonstrated methodology for performing clinical lab tests for identification of organisms and gave students an opportunity to replicate the methods and interpret results. Faculty thought the simulations were effective, but should not replace live lab sessions. Students agreed. In addition, animations to illustrate immunology concepts are in progress.

\section{B. Survey Results}

\section{Online Survey Results from Students}

Out of 356 students, there were 159 responses (45\% response). Selected survey results are listed below; the percentages of those choosing a given option are shown in parentheses.

For the lecture material, which learning materials do you use most often? (Select all that apply.) coursepack (92\%) attending lecture (60\%) 
MSU Medical Colleges Blended Learning for First Year Science Courses: Uniting Pedagogy to Maximize Experience and Real World Limitations

lecture recordings (audio \& screen) posted online (45\%)

scribe notes (43\%)

reviewing powerpoint slides posted online (16\%)

textbook (11\%)

What parts of classroom lectures do you find most helpful? (Select all that apply.)

live presentation by faculty (64\%)

live or video patient presentations (35\%)

note taking (34\%)

case studies (33\%)

filling in blanks in the coursepack (31\%)

questions from instructors to students (18\%)

small group activities (9\%)

hearing other people's questions (3\%)

opportunity to ask my own questions (3\%)

Of the online resources that you've used in your courses, which do you find most helpful? (Select all that apply.)

lecture recordings - audio/screen video (90\%)

practice exam questions and past exams (84\%)

Other options had less than $14 \%$ selection.

Of the following online resources, which would you use if available? (Select all that apply.)

practice exam questions and past exams (87\%)

lecture recordings - audio/screen video (84\%)

online activities to practice with content and improve recall (41\%)

online case studies (34\%)

web-based tutorials on specific topics (28\%)

\section{Focus Group Results From Students}

\section{a. Lectures and Interactivity}

Students agreed that large lectures in general are not very interactive. Use of an audience response system (clickers) can make lectures more interactive when the instructors use the system effectively, but technology problems can be very distracting. Examples of desired use included asking questions during the lecture and/or asking questions at the end as a self-test of understanding. Students also said that animations in lectures could make concepts easier to understand.

\section{b. Communication/Collaboration}

When students were asked about communication methods with other students, all said they used in-person communication. For other forms of communication, the number of students (14 total) who said they used each is as follows: phone -13 ; e-mail -10 ; instant messaging -7 . None of the students used chat 
rooms, discussion forums, wikis, blogs, or Facebook/My space. Student-created on-line repositories of study materials were frequently used.

When students were asked about communication methods with faculty, they agreed that e-mail is effective for asking questions, but communication with a faculty member is the last resort after trying to figure it out with peers. No students wanted to use a scheduled chat room for communication with faculty. They said chat rooms are inefficient and confusing, and it takes too long to get the response to your question. No students wanted to use a discussion thread/forum. Students who want to contact faculty often ask questions between classes or in laboratories.

\section{c. Online Resources, Including Case Studies}

In general students would like to see clinically oriented case studies that provide integration of content that they have already learned. If case studies are assigned and required, time needs to be allotted in the curriculum and the submission should be worth points. Students were asked which types of online materials they had used, and the most popular (with number of students using, out of 14, in parentheses) were: practice exam questions (14), Web-based tutorials on specific topics (13), online animations (12), online case studies (12). When asked about priority for implementation of new online resources, the highest rated categories were practice exam questions in an interactive format (with explanations), online case studies, online animations, examples of application/problem-solving, activities to practice applying content and improve recall.

\section{SUMMARY/CONCLUSIONS}

\section{A. Challenges and Benefits of Transition to Blended Learning Model}

In general, faculty are enthusiastic about enhancing content delivery and support the concept of blended learning. Through the discussions in this process a number of challenges to developing more online materials were identified, including:

Faculty time

Faculty technology skills

Understanding of types of online resources most likely to enhance curriculum and individual student learning with or without expansion

Institutional resources for technology support

Copyright restrictions and creation or finding appropriate Creative Commons images and diagrams Systematic plans for implementation, technical maintenance, updating content materials

Faculty agreed that more online learning materials, created to target difficult concepts and complement lectures, would be very beneficial. The online materials developed for Year 1 medical school courses could also be adapted for use in subsequent years, either as review for students or a framework for delivering more advanced content. It will take more time initially to transition to a blended learning model, but after online materials are created, faculty time could be used more effectively in interactive group formats, with less time spent in large lecture. It was anticipated that the outcome would be enhanced learning by all students in varied environments \& from varied backgrounds.

\section{B. Characteristics and Benefits of Repository for Re-Usable Learning Objects (RLO)}


Discussion of a repository led to preliminary planning of a searchable multimedia database that would contain (1) individual re-usable learning objects (e.g. images, diagrams, animations, digital audio/video lecture recordings) and (2) modules or collections of RLOs for self-instructional use, packaged in different ways for students at different levels of training. The repository would be a source of copyrightfree materials for faculty to use in lecture or online modules in multiple courses taught at different medical school levels. Some of the materials would be used directly by students, linked from course websites, as part of the blended curriculum. Individual images, diagrams, or animations could be obtained from Creative Commons materials submitted to sites such as Health Education Assets Library, MedEd Portal, or MERLOT, or could be created by MSU individuals. The existence of an easy-to-use, wellindexed repository would greatly facilitate the faculty efforts to design open educational resources.

\section{Outcomes Of BSDLI Process}

The student survey results were very important in consideration of prioritizing strategies for blended learning, since there is a constraint on the resources available. As a result of the outcomes of the online survey and the focus group discussions, the emphasis will be on development of online materials that better illustrate difficult concepts, e.g. through animations, and provide students with the opportunity to practice application of concepts in a clinical context as well as better learn concepts and facts with interactive practice questions.

During the year-long process, faculty became more involved in discussions of best practices, sharing ideas, developing intentional strategies for enhancing pedagogy, and working with instructional designers. They became much more aware of the issues of copyright restrictions for online use of materials. Faculty agreed that a searchable multimedia repository of images, re-usable learning objects (animations, online modules, etc.), and lecture recordings would be very valuable in curriculum delivery with online resources. They became more aware of both the challenges and the benefits of moving toward a blended curriculum, and how online resources could be effective in classes at remote sites.

\section{REFERENCES}

1. Bement, A. CyberInfrastructure Vision for $21^{\text {st }}$ Century Discovery. National Science Foundation: March, 2007. http://www.nsf.gov/publications/pub_summ.jsp?ods_key=nsf0728.

2. Bransford, J. D., A. L. Brown \& R. R. Cocking. How People Learn: Brain, Mind, Experience and School. National Research Council. Washington, D. C., National Academy Press. 2000.

3. Niemiec, M. \& G. Otte. Blended learning in higher education: A report from the Sloan-C 2005 Workshop.

4. Dziuban, C., J. Hartman, P. Moskal, S. Sorg \& B. Truman. Three ALN modalities: An institutional perspective. In J. Bourne \& J.C. Moore (Eds.), Elements of Quality Online Education: Into the Mainstream. Needham, MA: Sloan-C, 2004.

5. Schroeder, R. \& B. Oakley. Adding clicks to bricks: Increasing access to mainstream education. In J. Bourne \& J. Moore, (Eds.), Elements of Quality Online Education: Engaging Communities, 101115. Needham, MA: Sloan-C, 2005.

6. Garrison, D. R. \& H. Kanuka. Blended Learning: Uncovering its transformative potential in higher education. The Internet and Higher Education 7(2): 95-105, 2004.

7. Hiltz, S. R. \& M. Turoff. Education goes digital: The evolution of online and the revolution of higher education. Communications of the ACM 48(10): 59-65, 2005.

8. McCombs, B. \& D. Vakili. A learner-centered framework for e-learning. Teachers College Record 107: 1582-1600, 2005. 
9. Garrison, D. R., T. Anderson \& W. Archer. Critical Inquiry in a Text-based Environment: Computer Conferencing in Higher Education. Internet and Higher Education 11(2): 1-14, 2000.

10. Shea, P., C. S. Li \& A. Pickett. A study of teaching presence and student sense of elarning community in fully online and web-enhanced college courses. Internet and Higher Education 9: 175-190, 2006.

11. Karpicke, J. D. \& H. L. Roediger III. The Critical Importance of Retrieval for Learning. Science 319(5865):966-968, 15 February 2008.

12. Ruiz, J. G., M. J. Mintzer \& R. M. Leipzig. The Impact of E-Learning in Medical Education. Academic Medicine 81(3): 207-212, March 2006.

13. Effective Use of Educational Technology in Medical Education. Colloquium of Educational Technology: Recommendations and Guidelines for Medical Educators. Association of American Medical Colleges Institute for Improving Medical Education. March 2007.

\section{ACKNOWLEDGMENTS}

We wish to thank the following faculty, administrators and staff who have all contributed to the project. Faculty: R. Stephenson, F. Kennedy, A. Yang, C. Arvidson, D. Kreulen, J. Thornburg, J. Fitzsimmons, G. Aben, J. Wang, C. Wilkins; Administrators: A. Sousa, G. Riegle, P. Lovell, B. Guenther, C. Geith; Technology Support: G. Plantegenest, S. Way, J. Ford, P. Redovich, M. Hodgins, J. McDaniel, B. Blinkenberg, Virtual University Design and Technology producers, MSU Global staff.

We also wish to thank Sloan-C for allowing MSU to share this paper as a presentation at the 2008 Chicago Blended Learning Workshop.

\section{ABOUT THE AUTHORS}

Kathryn Lovell, Ph.D., is Director of Academic Computing and Year I Curriculum in the College of Human Medicine, and Professor, Dept. Neurology/Ophthalmology in the College of Osteopathic Medicine.

Karen Vignare currently serves as the Director of the Customer Experience for MSUglobal at Michigan State University. In that role, Karen is responsible for creating online entrepreneurial approaches for extending both non-credit and credit programs at MSU. 